\title{
Study on Interactive Relationship between Farm Products Trade and Farmers' Income Growth in China \\ --- Empirical Analysis Based on VAR Model
}

\author{
Jizhi Wang \\ School of Management, Hunan University of Science and technology \\ Xiangtan 411201, Hunan, China \\ E-mail: wjz506@sina.com \\ Yantao Wang \\ School of Management, Hunan University of Science and technology \\ Xiangtan 411201, Hunan, China \\ E-mail: wangyantaoking@sina.com
}

Foundation item: National Statistical Science Research Programs (2006B48); The Innovation Fund Project For Graduate Student of Hunan University of Science and Technology (S080133)

\begin{abstract}
Through establishing VAR Model, and applying modern cointegration theory and such methods of measurements as impact decomposition, this article probes into long term and short term interactive relations between Chinese farm products import \& export and growth of farmers' income. It is shown, in the long run, a stable equilibrium relationship exists between the three factors, and farm products export is the Granger cause for growth of farmers' income. In the short run, short term fluctuation of farmers' income is affected by short term changes of farm products import and export. And influence of short term changes on the part of farm products export is more obvious. Impact decomposition indicates that, impact of growth of farmers' income has a larger rate of contribution to farm products export and import.
\end{abstract}

Keywords: Farm products trade, Farmers' income, Long term equilibrium, Short term fluctuation, VAR Model

\section{Introduction}

Since the Reform and Opening-up in China, the overall income of Chinese farmers has witnessed an obvious growth, and the annual per capita net income of farmers has grown from 133.6 Yuan in 1978 to 3587 Yuan in 2006. However, by the middle and later periods of 1990s, the income growth rate of Chinese farmers had reduced in consecutive years, especially due to natural disasters, such as, the nationwide flood in 1998, the nationwide drought in 2006 and the frost and great earthquake in 2008. The issue of income growth of farmers has aroused great attention from the Central Committee of CPC. Thus, at the $16^{\text {th }}$ National Congress of Communist Party of China, it was pointed out, "Growth of farmers' income is an important task to build a well-off society in an all-round way". Furthermore, the Report of the $17^{\text {th }}$ National Congress of Communist Party of China also stipulated that "the core is to promote growth of farmers' income".

Growth of farmers' income has to be based on the premise of developing agricultural economy, and nowadays, with the globalization of economy, development of agricultural economy and increase of farmers' income is necessarily inseparable from farm products trade. Especially for the time being, China has become the fourth largest farm product import nation and the fifth largest farm product export nation, and its farm product trade turnover increased from 6.1 billion USD in 1978 to 78.1 billion USD in 2007, with an average annual increase of $9.2 \%$. Although from the intuitive perspective, Chinese farm product import and export has driven growth of farmers' income, there still exist such 
problems: Does a long term and stationary interactive relation exist between them? How they interplay within a short period of time? This is an elementary issue related with growth of farmers' income and development of farm product trade. This article is going to conduct an empirical study on the interactive relation between farm product trade and growth of farmers' income in China by means of VAR model, in the hope to draw up scientifically policy of farm product trade in China and to provide theoretical evidence for policy of farmers' income increase.

\section{Relevant literature review}

Researchers have conducted studies from different perspectives on the issue of increase of farmers' income. Starting from the relationship between industrialization and urbanization, Li Mengjue (2008) holds the viewpoint that both industrialization rate and urbanization rate are positively correlated with net income of farmers, and that acceleration of the process of industrialization and urbanization and development of the tertiary industry are the three motivations to increase income of farmers. Taking data as a sample from 128 peasant households from 2000 to 2006, Ma Yu, Xu Xiaoyang and Han Cun (2008) study on-the-spot transfer of agricultural workforce in rural areas and influences of increasing non-agricultural industry investment on growth of farmers' income. Through establishing Douglas functional model, Li Jianzhong, Wang Hui and Wang Min (2007) analyze influences of rural human capital on income of farmers. By means of establishing effective rural public product supply system, Zhang Xiusheng, Liu Fang and Wang Junmin (2007) conclude that rural public product supply system can increase value added of agricultural production, lighten the burden on the peasants and decrease the quantity of peasants, which together may promote income growth of farmers in China. After summarizing the relational theory and empirical analysis of financial development and economic \& income growth, Yang Wen (2007) builds a model between Chinese rural financial development and growth of farmers' income, and comes to the conclusion that a significant correlativity exists between rural financial development and growth of farmers' income, in the form of complex and bidirectional causality.

Although there have been a great number of studies on the problem of increase of farmers' income in China, there are fewer studies on growth of farmers' income from the perspective of farm product trade. Through analysis, Wang Yanfei and Zeng Guoping (2006) discovered that farm product export was the cause for growth of farmers' income, and a long term and stationary equilibrium relation existed between the two. Resorting to data about changes of farm product import and farmers' income from 1981 to 2003, Zhang Peng and Xie Bingbing (2007) conducted a Granger Causality Test on relations between changes of farm product import and farmers' income. According to them, Granger causality did not exist between the two within a short period of time, but it would appear in the long run. From the perspective of the relation between farm product trade and farmers' income, Wang Peizhi and Liu Ning (2007) discussed new approaches to growth of farmers' income in construction of the new socialist countryside. Applying data about farm product trade and income of farmers from 1981 to 2007, Tao Xiuling and Zhang Peng (2009) probed into the relation between the total volume of farm product trade and income of farmers by means of the Cointegration Test, and by establishing Vector Error Correction Model (VECM) and Granger Causality Test.

The above studies have revealed the following characteristics: firstly, there have been a great many studies to explore the problem of growth of farmers' income from the perspective of rural urbanization, transfer of rural labor, rural human capital, rural public product supply and rural finance, etc, while there have been fewer studies from the perspective of farm product trade; secondly, even if there have been studies which combines farm product trade with farmers' income, they just commence from a certain aspect of farm product trade import, export or total export-import volume, but relatively few studies to explore growth of farmers' income by combining farm product import and export.

\section{Measurement model and explanation of data}

\subsection{Measurement model}

Vector Autoregression (VAR) is to build a model based on the statistical property of data, which was put forward by Sims (C. A. Sims, 1980) for the first time. VAR Model constructs a model by taking each endogenous variable as the function of lagged value of all endogenous variables in a system, so as to expand univariate Vector Autoregression Model into "Vector" Autoregression Model constituted by variables of multivariate time series. Application of VAR Model is not only convenient for examining whether a stationary relation exists between all variables in the model in the long run, but makes it unnecessary to make an aforehand presupposition on the endogenousness and exogenousness of variables in the model. The mathematical expression of VAR (p) Model is as follows:

$$
\mathrm{Y}_{\mathrm{t}}=\mathrm{A}_{1} \mathrm{Y}_{\mathrm{t}-1}+\mathrm{A}_{2} \mathrm{Y}_{\mathrm{t}-2}+\cdots+\mathrm{A}_{\mathrm{P}} \mathrm{Y}_{\mathrm{t}-\mathrm{p}}+\varepsilon_{\mathrm{t}} \quad \mathrm{t}=1,2, \ldots, \mathrm{T}
$$

In this article, the authors select the variable $\mathrm{Y}_{\mathrm{t}}=(\ln \mathrm{n}, \operatorname{lnEX}, \operatorname{lnIM})^{\prime}$, among which $\mathrm{R}$ stands for the level of farmers' income, EX stands for the export volume of farm product trade, and IM stands for the import volume of farm product trade. $A_{1}, \ldots A_{P}$ represents $3 \times 3$ matrix, $p$ represents lagged orders, $T$ represents the number of samples and $\varepsilon_{t}$ represents the flat noise. 


\section{2 data specification}

The sample data used in this article are all annual data, and the period of samples is from 1985 to 2007. All sample data originate from "Chinese Agricultural Development Report in 2007", "China Economy Statistics Database" in China Economic Information Network, and "Food and Agriculture Organization of the United Nations". The data of farmers' income $(\mathrm{R})$ is deflated by the consumer price index $(1978=100)$ to eliminate influence of price fluctuation. Farm product import turnover (IM) and export turnover (EX) are firstly converted into the number of RMB according to the exchange rate of RMB to USD each year, and then are deflated by the consumer price index. Since the natural logarithmic transformation of data will not change original cointegration relation, can linearize the tendency and eliminate the phenomenon of heteroscedasticity in time series, natural logarithmic transformation is made respectively to the income of farmers (R), farm product export turnover (EX) and farm product import turnover (IM), expressed respectively in the form of $\operatorname{lnR}, \ln E X$ and $\operatorname{lnIM}$.

\section{Study on the long term equilibrium relation between growth of farmers' income and farm product trade}

Usually, traditional regression methods assume that the time series applied are stationary. However, as a matter of fact, time series of lots of economic phenomena are nonstationary, which would result in the phenomena of "false" regression and "meaningless" regression if explained by means of traditional Ordinary Least Squares. The cointegration theory and methods proposed by Engle and Granger (1987) provide another approach for model building of nonstationary series. Although some economic variables are nonstationary series, their linear combination might turn out to be stationary. This sort of stationary linear combination is termed as cointegration equation and can be explained as a long term and stationary equilibrium relation between variables. Since only variables with similar single cointegration orders have the relationship of cointegration, we should, first of all, conduct a unit root test on the variables mentioned.

\subsection{Test on stationarity of variables}

In this article, the author adopts the method of ADF (Augmented Dickey-Fuller) to conduct the test on unit root of series. The test is based on the following regression equation:

$$
\Delta \mathrm{y}_{\mathrm{t}}=\alpha_{0}+\alpha_{1} \mathrm{t}+(\rho-1) \mathrm{y}_{\mathrm{t}-1}+\sum_{\mathrm{i}=1}^{\mathrm{p}} \beta_{\mathrm{i}} \Delta \mathrm{y}_{\mathrm{t}-\mathrm{i}}+\varepsilon_{\mathrm{t}}
$$

The original hypothesis $\mathrm{H}_{0}: \rho=1$, and the alternative hypothesis $\mathrm{H}_{1}: \rho<1$. Acceptance of the original hypothesis means that time series contain a unit root. Results of test on variables are shown in Table 1. According to test results in Table 1, for all series, the hypothesis of a unit root above the significance level of $5 \%$ can not be rejected. After the first order difference, all variables are above the significance level of $5 \%$, so the nonstationary original hypothesis can be rejected, that is, all variable series are I(1).

\section{Insert Table 1 Here}

\subsection{Johansen cointegration test}

Results of unit root test indicate that all variable series in the VAR Model are I(1), that is, they are equipped with necessary conditions for constructing cointegration equation sets. This article applies the method of multivariable Johansen cointegration test to conduct a cointegration test on farm such variables as farm product import turnover, farm product export turnover and income of farmers, as is shown in Table 2 and Table 3.

\section{Insert Table 2 Here}

\section{Insert Table 3 Here}

Results of test in Table 2 indicate, above the significance level of $5 \%$, there is a unique cointegration equation between farm product export \& import in China and farmers' income, which can be expressed as follows after standardization:

$$
\ln (R)=0.895383+0.706740 \ln (E X)+0.234513 \ln (I M)+\varepsilon_{t}
$$

The cointegration equation (3) indicates, a long term and stationary equilibrium relation exists between farm product export \& import in China and growth of farmers' income. Specifically speaking, in the long run, elasticity of farm product export and import to income of farmers is both positive value. An increase of $1 \%$ in farm product export (EX) will give rise to an increase of $0.706740 \%$ in income of farmers (R), and an increase of $1 \%$ in farm product import (IM) will give rise to an increase of $0.234513 \%$ in income of farmers $(\mathrm{R})$. Hence, in the long run, changes of farm product import and export in China both have great influences upon growth of farmers' income, while contribution of farm product export to growth of farmers' income is greater than that of farm product import.

\subsection{Test on Granger causality between variables}

Cointegration test results certify a long term and stationary equilibrium relation exists between LnR and LnEX \& LnIM, 
but it is open for further test whether this equilibrium relation constitutes a relation of causality. In this article, the authors resort to the Granger Test of Causality proposed by Granger (1969) to make an analysis on this issue. Below the level of the significance level $\alpha=0.05$, the Granger Causality Test on all variables is shown as in Table 4 .

\section{Insert Table 4 Here}

From Table 4, it is obvious that a bidirectional Granger causality exists between LnR and LnEX; a single Granger causality exists between LnR and LnIM, and LnIM has a Granger causality towards LnR; there does not exist a Granger causality between LnEX and LnIM. That is, growth of farmers' income promotes development of farm product export, but does not have an obvious effect on development of farm product import; farm product import and export affect growth of farmers' income to a great extent.

\section{Analysis on short-term dynamic effects of growth of farmers' income and farm product trade}

\subsection{Vector Error Correction Model (VECM)}

Cointegration Model reveals the long-term convergent behaviors between variables from the perspective of the coordinated development changes among them. According to the representation theorem of Granger, if the cointegration relation exists between numerous non-stationary variables, then there must exist the expression form for error correction. An item of error correction reflects influences of deviation of relationship between variables from the long-term equilibrium state upon changes within a short period of time. In the following, we are going to discuss the Vector Error Correction Model among variables of farm product trade and variables of growth of farmers' income and observe the short-term equilibrium relationship between different variables. The duration of lag 1 is determined according to the norms of AIC and SC, and the following is the matrix form of VECM.

$$
\begin{aligned}
& \left(\begin{array}{c}
\Delta \ln (R)_{t} \\
\Delta \ln (E X)_{t} \\
\Delta \ln (I M)_{t}
\end{array}\right)=\left(\begin{array}{c}
-0.240137 \\
0.651308 \\
-0.697788
\end{array}\right) * v^{2}{ }^{2} m_{t-1}+\left(\begin{array}{c}
0.649668 \\
0.888356 \\
-0.825822
\end{array}\right) * \Delta \ln (R)_{t-1}+\left(\begin{array}{l}
-0.120600 \\
0.030371 \\
0.661396
\end{array}\right) \\
& * \Delta \ln (E X)_{t-1}+\left(\begin{array}{c}
-0.030836 \\
0.045676 \\
-0.828447
\end{array}\right) * \Delta \ln (I M)_{t-1}+\left(\begin{array}{l}
0.058718 \\
0.011860 \\
0.222802
\end{array}\right)
\end{aligned}
$$

In the formula, vecm $m_{t-1}$ stands for cointegration relationship vector (or error correction item), $\mathrm{t}$ stands for

root-mean-square error and the value of the matrix before $v e c m_{t-1}$ stands for adjustment coefficient.

$$
\begin{gathered}
\text { vecm }_{t-1}=\ln (R)_{t-1}-0.706740 \ln (E X)_{t-1}-0.234513 \ln (I M)_{t-1}-0.895383 \\
\mathrm{t}: \quad(0.12838)
\end{gathered}
$$

In the above error correction model (4), fluctuation of the variable explained can be seperated into two parts: one part is influences of short term fluctuation and the other part is influence due to deviation from the long term equilibrium. The value of the coefficient of the error correction item $v \mathrm{~cm}_{\mathrm{t}-1}$ reflects adjustment strength to deviation from the long term equilibrium. The adjustment coefficients of farmers' income, farm product export and farm product import are respectively $-0.240137,0.651308$ and -0.697788 . At the same time, the farm product export turnover and import turnover in the previous year affect the growth extent of farmers' income next year respectively with the value of -0.120600 and -0.030836 .

\subsection{Analysis on impulse response function}

An error variance predicted by time series is the outcome of common effects of its own disturbance and other disturbance in the system. Impulse response function describes impulse of a disturbance term added with a root-mean-square error, and also influences of the current value and future value of endogenous variables, which can intuitively reflect the dynamic interaction and effect between variables.

According to study by Ender (1995), through test, the structure of VAR Model in this article is stationary, and the reciprocals of all latent roots are smaller than 1 (the evaluation and test process is neglected). In order to give a vivid 
description of the dynamic relationship between farm product import \& export and growth of farmers' income, the authors of the article are going to apply the impulse response function to analyze the dynamic characteristics of the model.

\section{Insert Figure 1 Here}

As in shown in Figure 1, when a positive standard deviation impulse is given to income of farmers, that is, the income of farmers' is increased, then the impulse effect of the income itself increases rapidly at the beginning and starts to reach a plateau in the Period 13. Response of farmers' income to farm product import \& export should be always positive impulse. In the transition period from Period 1 to Period 2, the impulse effects of farm product import and export are quite similar, but after Period 2, impulse effect of farm product export grows rapidly, obviously higher than impulse of farm product import to the income of farmers. Thus, it can be seen that the driving force of farm product export on growth of farmers' income is higher than that of farm product import to grwoth of farmers' income, which corresponds with the result of cointegration test.

\section{Insert Figure 2 Here}

Figure 2 reveals response of farm product export to impulse of all variables. Firstly, its impulse response to growth of farmers' income is obvious, and presents a strong positive effect at the very beginning, increasing until Period 10 when the positive effect approaches a plateau. This proves that the positive effect of growth of farmers' income upon farm product export does not only present a trend of increasing progressively, but also will last for a long time in the long run. However, response of impulse of farm product import is always a negative effect, and reaches its minimum value in Period 2. This proves that a harmonious development has not been achieved in farm product trade in terms of import and export in China.

\section{Insert Figure 3 Here}

From Figure 3, it is obvious that impulse of all variables to farm product import is positive effect. Response of farm product import to its own impulse is extremely non-stationary at the beginning, fluctuating repeatedly, and gradually becomes stationary by the Period 16. Impulse of farm product import to farm product export gradually grows at the beginning, and reaches its maximum value by the Period 12. Impulse of farm product import to growth of farmers' income has always been stationary, but fluctuates slightly at the beginning, which proves that growth of farmers' income has a stable and stimulative effect on farm product import, and promotes growth of import turnover.

\subsection{Variance decomposition}

Variance decomposition means that, when a certain variable in the system is shocked by a unit, then it will reflect the degree of interaction between variables in the form of predicted error variance of the variable, and its fundamental idea is to decompose, based on causes of formation, each endogenous variable in the system into all components correlated with the random disturbance term (information) in each equation, so as to understand the relative importance of all information to endogenous variables of the model. The following is the diagram of variance decomposition of all variables.

\section{Insert Figure 4 Here}

Figure 4 is the diagram of variance decomposition of growth of farmers' income. At the beginning, growth of farmers' income is merely affected by itself, which is as a result of the fact that LNY is regarded as the first dependent variable in the establishment of VAR Model. With time going on, the contribution rate of variance of growth of farmers' income gradually becomes smaller, whereas the contribution rate of variance of farm product export and import gradually becomes larger. In Period 1 and Period 2, rate of contribution of farm product export to growth of farmers' income obviously increases, larger than that of farm product import to growth of farmers' income. Finally, the rate of contribution of farm product export and import to growth of farmers' income is respectively $21.6 \%$ and $3.3 \%$.

\section{Insert Figure 5 Here}

Figure 5 gives the results of variance decomposition of all variables to farm product export. The Rate of contribution of farm product export to itself gradually reduces with time going on, and the speed of reduction from Period 1 to Period 4 is rapid. However, it slowly reduces from Period 4 and keeps stationary by the Period 12, finally keeping around $14.6 \%$. The rate of variance contribution of growth of farmers' income and farm product import gradually increases, and growth of farmers' income presents a significant contribution rate at the very beginning, always larger than the rate of contribution of farm product import to farm product export. Ultimately, the contribution rate of income of farmers keeps around $85 \%$ and the contribution rate of farm product import keeps around $0.38 \%$, which corresponds with the Granger Causality Test result.

\section{Insert Figure 6 Here}

Figure 6 reveals variance decomposition of farm product import. It can be seen, rate of the contribution of growth of 
farmers' income to farm product import is less significant than that to farm product export. At the beginning, the contribution rate of the former gradually increases, and finally keeps around $15.1 \%$, which corresponds with the Granger Causality Test result that "growth of farmers' income is the Granger cause for farm product export but not Granger cause for farm product import". Rate of contribution of farm product import to itself gradually reduces with time going on, and finally keeps around $52.0 \%$. The rate of contribution of farm product export to farm product import increases at the beginning and reaches its maximum value by the Period 2. Then. It reaches a plateau and finally the contribution rate is maintained around $32.9 \%$.

\section{Conclusions}

By means of VAR Model, this paper has conducted a cointegration test on the relations between farm product import, export and growth of farmers' income from the year 1985 to 2007, and, based on this, carries out Granger Causality Test, and establishes Vector Error Correction Model (VECM). Then, the authors analyze the dynamic effect mechanism among the three variables by means of impulse response function and variance decomposition and comes to the following conclusions.

Although time series between growth of farmers' income, farm product trade export and import are nonstationary, the linear combination between them is stationary. That is to say, a long term and stationary equilibrium relationship exists between the three variables. There is a bidirectional Granger Causality between farm product export and growth of farmers' income, and a uni-directional Granger Causality between farm product import and growth of farmers' income, whereas there doesn't exist the Granger Causality between farm product export and farm product import.

From the short-term dynamic equation established, that is, Vector Error Correction Model, it can be seen that, the growth of current farmers' income is accumulatively influenced by the laggard period of its own, gradually weakened, and the coefficient of the influence is smaller than 1. Simultaneously, growth of farmers' income is influenced by the current period and the laggard period of farm product import and export, with the influence of the laggard period being more significant. The short term fluctuation of farm product export has obvious effect upon the short term changes of growth of farmers' income, which indicates that stationarity of farm product export plays a noticeable role for maintaining the stationary significance of growth of farmers' income.

Considering the ultimate impulse response analysis and variance decomposition, either farm product export or farm product import exerts great impulse response on growth of farmers' income, and will keep this stationary impulse response within a long period of time. Both farm product export and farm product import have contributions to growth of farmers' income, and the former has greater effect on growth of farmers' income. Growth of farmers' income exerts a positive impulse on both farm product import and farm product export, and its rate of contribution to both of the two variables is large. Therefore, stable growth of farmers' income plays a significant role in maintaining equilibrium of farm product trade in China.

\section{References}

Gao, Tiemei. (2006). Econometric Analysis and Modeling --- Applications and Examples of Eviews. Tsinghua University Press, 249-250, 154-168.

Li, Jianzhong, Wang, Hui \& Wang, Min. (2007). Influences of Rural Human Capital on Farmers' Income. China Statistics, (7):27-28.

Li, Mengjue. (2008). An Empirical Analysis on the Relationship between Development of Urbanization and Industrialization and Increase of Farmers' Income. Economic Review, (6):72-74.

Ma, Yu, Xu, Xiaoyang \& Han, Cun. (2008). On Labor Shift, Non-Agricultural Investment and Increase of Farmer Incomes. Finance and Trade Research, (2):25-31.

Tao, Xiuling \& Zhang, Peng. (2009). Empirical Study on Influences of Farm Products Trade on Farmers' Income. Northern Economy, (5):36-38.

Wang, Peizhi \& Liu, Ning. (2007). Example Studies on the Agriculture Goods for the Peasants to Improve the Incoming. Journal of Shandong Agricultural University (Social Science Edition), (1):8-12.

Wang, Yanfei \& Zeng, Guoping. (2006). Contribution of Agricultural Export to the Growth in Farmers' Income in China. International Business --- Journal of University of International Business \& Economics, (4):32-36.

Yang, Wen. (2007). Study on the Causality between Chinese Rural Financial Development and Increase of Farmers' Income. Research of Financial \& Accounting, (11):73-76.

Zhang, Peng \& Xie, Bingbing. (2007). Empirical Study on the Mutual Effect of Farm Product Import and Farmers' Income. Journal of International Trade, (12):30-33.

Zhang, Xiusheng, Liu, Fang \& Wang, Junmin. (2007). Increase of Farmers' Income: Analysis Based on the Perspective of Rural Public Products Supply. Economic Review, (3):48-55. 
Table 1. Results of ADF unit root test

\begin{tabular}{llcccc}
\hline & & \multicolumn{3}{c}{ T statistic } \\
\cline { 4 - 6 } Variables & ADF test value & $\begin{array}{c}\text { Test types } \\
(\mathrm{c}, \mathrm{t}, \mathrm{k})\end{array}$ & $1 \%$ critical value & $5 \%$ critical value & $10 \%$ critical value \\
\cline { 4 - 6 } LnR & -0.886321 & $(\mathrm{c}, 0,2)$ & -3.808546 & -3.020686 & -2.650413 \\
LnEX & 2.435955 & $(0,0,1)$ & -2.679735 & -1.958088 & -1.607830 \\
LnIM & -1.025873 & $(\mathrm{c}, 0,1)$ & -3.788030 & -3.012363 & -2.646119 \\
$\triangle(\mathrm{LnR})$ & $-3.105658 * *$ & $(\mathrm{c}, 0,2)$ & -3.831511 & -3.029970 & -2.655194 \\
$\triangle(\mathrm{LnEX})$ & $-2.739441 * * *$ & $(0,0,1)$ & -2.685718 & -1.959071 & -1.607456 \\
$\triangle(\mathrm{LnIM})$ & $-3.677435 * *$ & $(\mathrm{c}, 0,1)$ & -3.808546 & -3.020686 & -2.650413 \\
\hline
\end{tabular}

Note: ** means being significant above the level of $5 \%$; *** means being significant above the level of $1 \%$; $\triangle$ stands for first order difference; $\mathrm{c}$ in the types of the test stands for a constant item, and t represents the lagged orders, which are determined by the optimal information standard of AIC and SC.

Table 2. Results of Johansen cointegration test

\begin{tabular}{lllll}
\hline Eigenvalue & Trace Statistics & $5 \%$ critical value & $1 \%$ critical value & $\begin{array}{l}\text { Assumption of the number of } \\
\text { cointegration equations }\end{array}$ \\
\hline & & & & None * \\
0.649566 & 35.37021 & 29.79707 & 35.45817 & At most 1 \\
0.045517 & 0.978290 & 3.841466 & 6.634897 & At most 2 \\
\hline
\end{tabular}

Note: * means the original hypothesis is rejected above the significance level of 5\%. The lagged order 1 is selected. Selection of lag phase is in accordance with the minimum value of AIC and SC.

Table 3. Cointegration vectors after standardization

\begin{tabular}{cccc}
\hline $\ln (\mathrm{R})$ & $\ln (\mathrm{EX})$ & $\ln (\mathrm{IM})$ & $\mathrm{C}$ \\
\hline 1.000000 & -0.706740 & -0.234513 & -0.895383 \\
& $(0.12838)$ & $(0.12651)$ & \\
\hline Log likelihood & 54.65948 & & \\
\hline
\end{tabular}

Note: Data in the bracket are standard errors 
Table 4. Results of test on Granger causality between variables

\begin{tabular}{|c|c|c|c|c|c|}
\hline null hypothesis $\mathrm{H}_{0}$ & Obs & Lags & F-statistic & Probablity & Conclusion \\
\hline lnEX not Granger cause $\ln R$ & 19 & 4 & 4.47159 & 0.02495 & $\mathrm{H}_{0}$ rejected \\
\hline lnR not Granger cause $\operatorname{lnEX}$ & & & 4.47359 & 0.02491 & $\mathrm{H}_{0}$ rejected \\
\hline lnIM not Granger cause $\ln R$ & 19 & 4 & 6.56911 & 0.00736 & $\mathrm{H}_{0}$ rejected \\
\hline lnR not Granger cause lnIM & & & 0.63320 & 0.65022 & $\mathrm{H}_{0}$ rejected \\
\hline lnIM not Granger cause lnEX & 19 & 4 & 0.67184 & 0.62635 & $\mathrm{H}_{0}$ rejected \\
\hline lnEX not Granger cause lnIM & & & 0.99316 & 0.45468 & $\mathrm{H}_{0}$ rejected \\
\hline
\end{tabular}

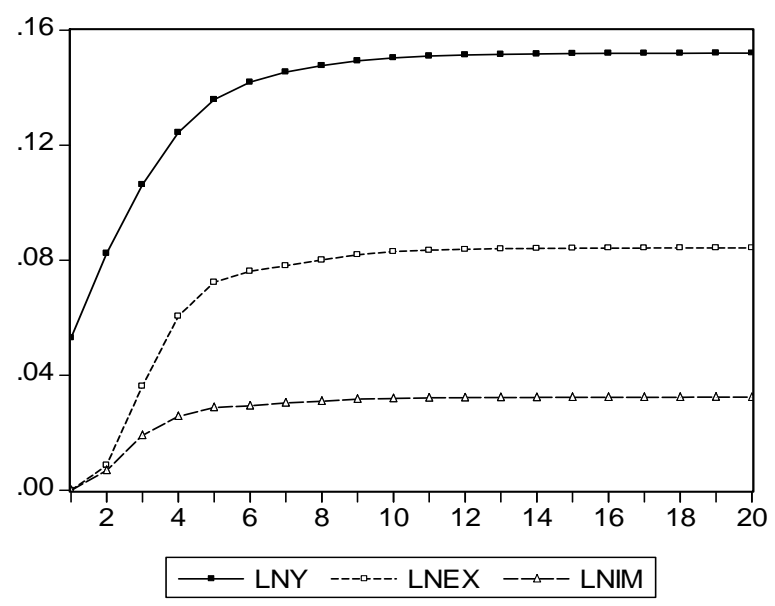

Figure 1. Response of farmers' income to all variables

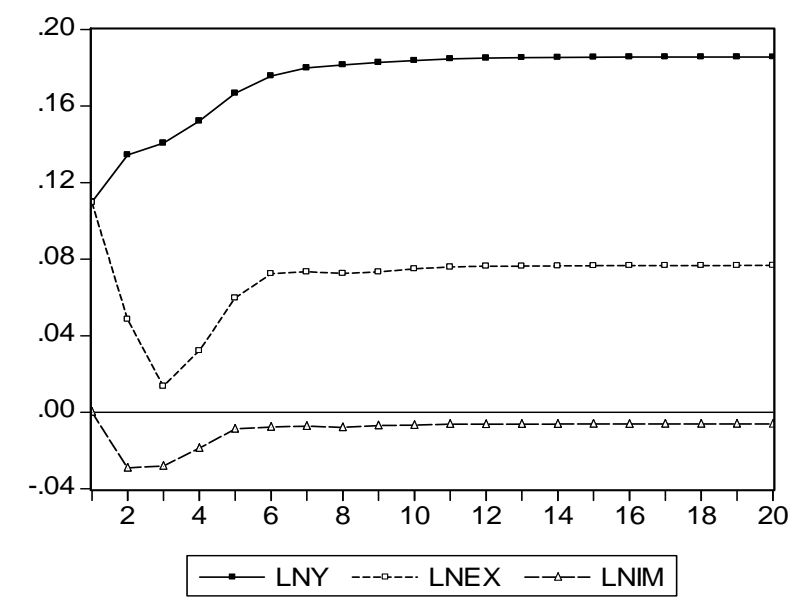

Figure 2. Response of farm product export to all variables 


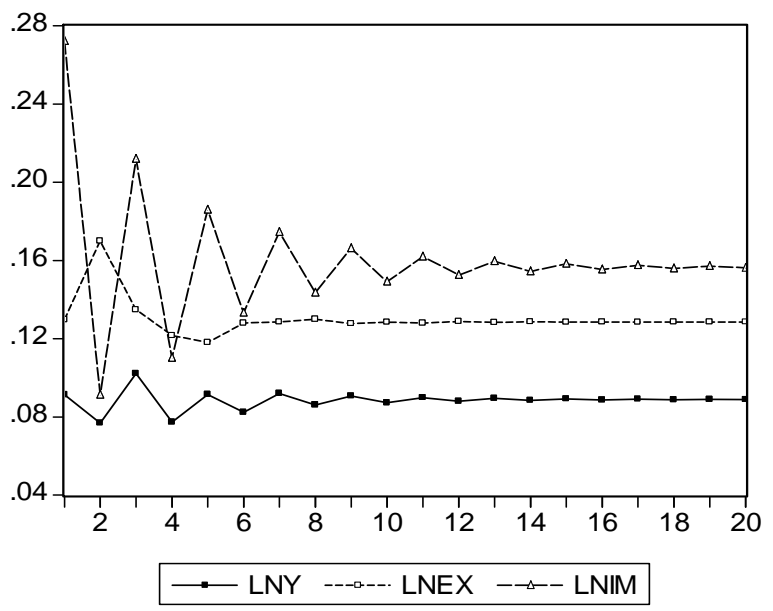

Figure 3. Response of farm product import to all variables

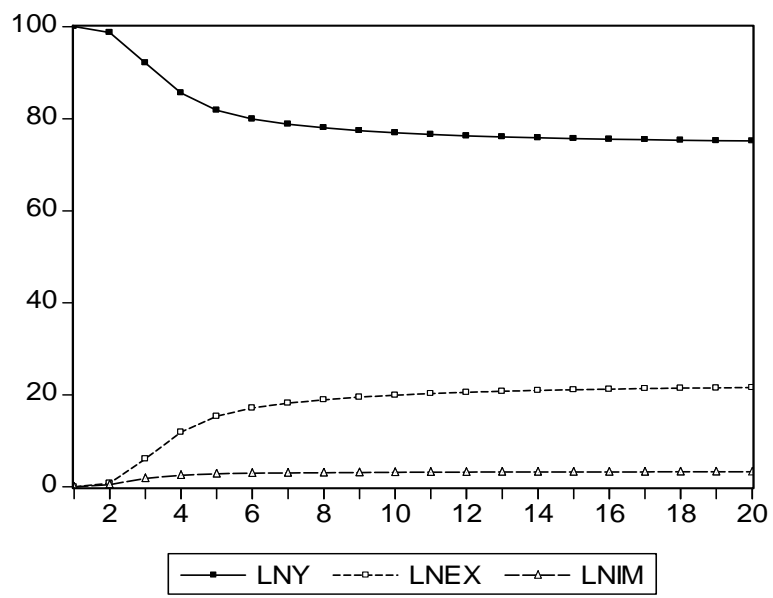

Figure 4. Variance decomposition of growth of farmers' income

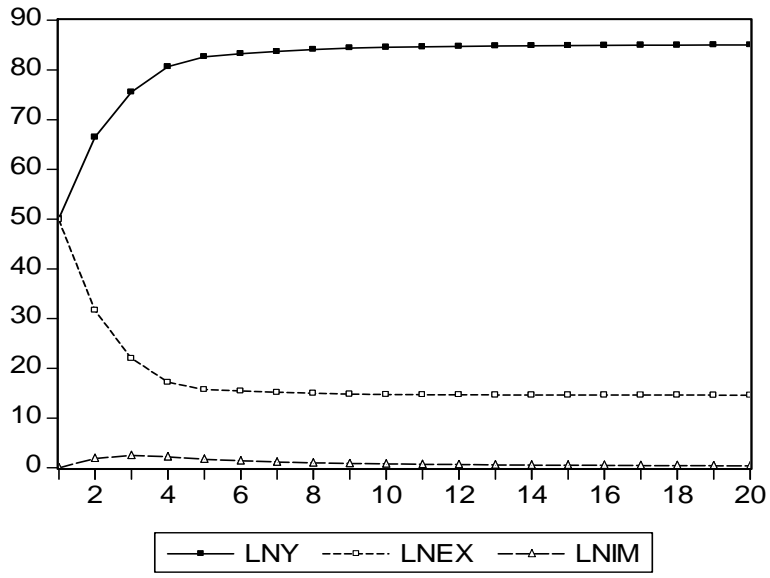

Figure 5. Variance decomposition of farm product export 


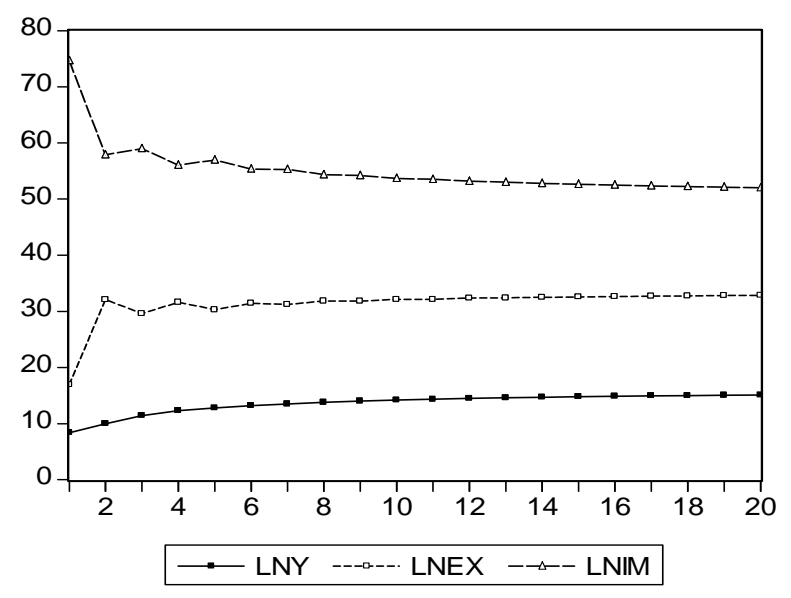

Figure 6. Variance decomposition of farm product import 